\title{
Metal-free and Alkali-metal-catalyzed Synthesis of Isoureas from Alcohols and Carbodiimides
}

\author{
Arnaud Imberdis, Guillaume Lefèvre, Pierre Thuéry, and Thibault Cantat*[a]
}

Dedicated to Dr. Michel Ephritikhine on the occasion of his $70^{\text {th }}$ birthday.

\begin{abstract}
The first addition of alcohols to carbodiimides catalyzed by transition metal-free compounds is reported, using 1,5,7triazabicyclo[4.4.0]dec-5-ene (TBD) and its alkali metal salts. Isoureas are obtained in short reaction times and high yields, using TBDK. Control of the coordination sphere of potassium with exogenous chelating ligands, combined with mechanistic DFT calculations, demonstrates the role and positive influence of the alkali cation on the kinetics.
\end{abstract}

Isomers of ureas, isoureas are common organic compounds used in agriculture (herbicidal activity ${ }^{[1 \mathrm{a}]}$ or stimulating growth ${ }^{[1 \mathrm{~b}]}$ ), medicine (stimulating effect on smooth muscles ${ }^{[1 \mathrm{c}]}$, antiinflammatory drugs ${ }^{[1 \mathrm{~d}]}$ ), chemical physics (surfactants ${ }^{[1]}$ ) and biochemistry ${ }^{[1-g]}$. While ureas are quite acidic $\left(\mathrm{pK}_{\mathrm{a}}=1\right)$, isoureas are stronger Brønsted bases and their $\mathrm{pK}_{\mathrm{a}} \mathrm{s}$ range from 6 to 10 . Their unique and rich reactivity has been exploited in the palladium-catalyzed olefination of ketones, in the presence of phosphines, and in the $\mathrm{O}$ - and $\mathrm{N}$-alkylation of weak nucleophiles, such as carboxylic acids and imides, respectively (Scheme 1). ${ }^{[2]}$ Chapman rearrangements enable the formation of $\mathrm{N}$-phenylureas from O-phenylisoureas. ${ }^{[2 \mathrm{c}]}$

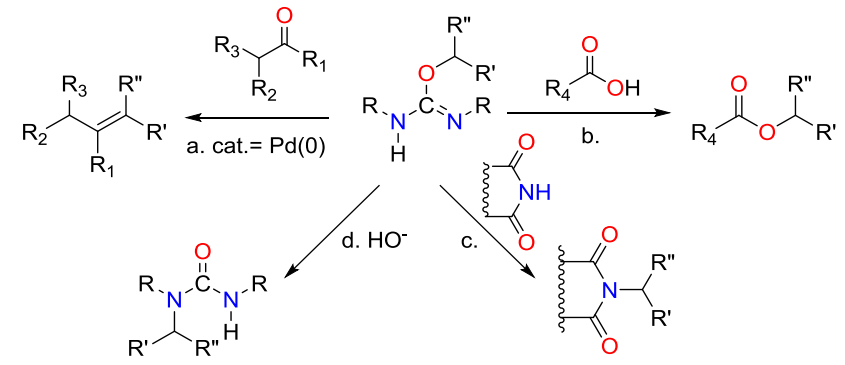

Scheme 1. C-alkylation reaction between isoureas and ketones catalyzed by $\mathrm{Pd}^{0}$ in the presence of 1 equiv. $\mathrm{PPh}_{3}(\mathrm{a}), \mathrm{O}$-alkylation of carboxylic acids (b), $\mathrm{N}$ alkylation of imides (c), Chapman rearrangement (d).

The synthesis of isoureas by addition of an alcohol onto a carbodiimide $\mathrm{RN}=\mathrm{C}=\mathrm{NR}$ has the advantage of being atom efficient and of utilizing readily available starting materials. Yet, carbodiimides are less electrophilic than other heterocumulenes such as isocyanates. Whereas alcohols react at room temperature with isocyanates (to provide carbamates), their reaction with carbodiimides requires a thermal activation or a catalyst. State-of-the-art catalysts are based on transition metal and actinide complexes. Copper $\left(\mathrm{CuCl}, \mathrm{CuCl}_{2}, \mathrm{Cu}_{2} \mathrm{O}\right)^{[3 \mathrm{a}-\mathrm{f}]}$ and zinc $\left(\mathrm{ZnCl}_{2}\right)$ salts $^{[3 \mathrm{~g}]}$ are reported to act as Lewis acids, able to

[a] A. Imberdis, Dr. G. Lefèvre, Dr. P. Thuéry, Dr. T. Cantat NIMBE, CEA, CNRS, Université Paris-Saclay, CEA Saclay 91191 Gif-sur-Yvette cedex, France

Fax: (+33) 1.6908.6640

E-mail: thibault.cantat@cea.fr enhance the electrophilicity of the carbodiimide reagent. In 2016, Eisen reported new actinide complexes ${ }^{[4]}\left(\mathrm{U}\left[\mathrm{N}\left(\mathrm{SiMe}_{3}\right)_{2}\right]_{3}\right.$ and $\left[\left(\mathrm{Me}_{3} \mathrm{Si}\right)_{2} \mathrm{~N}\right]_{2} \mathrm{An}\left[\mathrm{K}^{2}(\mathrm{~N}, \mathrm{C})-\mathrm{CH}_{2} \mathrm{Si}\left(\mathrm{CH}_{3}\right)_{2} \mathrm{~N}\left(\mathrm{SiMe}_{3}\right)\right](\mathrm{An}=\mathrm{Th}$ or $\left.\mathrm{U})\right)$ able to catalyze the formation of isoureas under mild conditions. Mechanistic data suggested that the actinide complexes increase the nucleophilicity of the alcohol reagent by deprotonation, in the coordination sphere of the $U^{I V}$ or $\mathrm{Th}^{\mathrm{IV}}$ ion. Capitalizing on these mechanistic trends, we describe herein the first transition metalfree catalysts able to promote the addition of alcohols to carbodiimides, using 1,5,7-triazabicyclo[4.4.0]dec-5-ene (TBD) and its alkali metals salts TBDNa and TBDK. Control of the coordination sphere of the alkali metal with exogenous ligands, combined with DFT calculations, offers a new vision on the active role of alkali metal cations in catalysis.

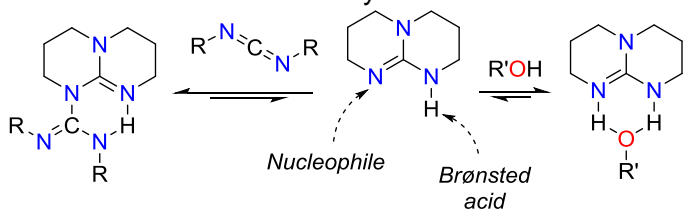

Scheme 2. Ambiphilic activation of alcohols and carbodiimides by TBD.

TBD is a symmetric guanidine combining a nucleophilic $\mathrm{N}$ center and a Lewis acidic $\mathrm{N}-\mathrm{H}$ group. Hedrick, Waymouth et al. showed that TBD can efficiently catalyze the addition of amines onto esters, leading to the formation of amides. ${ }^{[5 a]}$ Interestingly, Méreau et al. exemplified, based on DFT calculations, how the ambiphilicity of TBD plays a crucial role in the ring opening reaction of cyclic carbonates. ${ }^{[5 b]}$ Several reports also highlighted the importance of bifunctional $\mathrm{H}$-bonded adducts (involving for example an alcohol, Scheme 2) as key intermediates in guanidine-catalyzed systems, such as Strecker, ${ }^{[5 c]}$ Michael, ${ }^{[5 d]}$ or phospha-Michael[5e] reactions. ${ }^{[5]]}$ TBD is also an ideal candidate for the activation of both alcohols and carbodiimides and our group reported the activation of alcohols and their subsequent addition to $\mathrm{CO}_{2}$, under stoichiometric conditions. ${ }^{[6 a]}$ In addition, TBD reacts with a variety of heterocumulenes, including carbodiimides, to yield stabilized adducts (Scheme 2).[6b] The potential of TBD to serve as a catalyst in the formation of isoureas from alcohols and carbodiimides was hence tested by reacting methanol and diisopropylcarbodiimide (DIC), in the presence of $5.0 \mathrm{~mol} \% \mathrm{TBD}$, in benzene. After $24 \mathrm{~h}$ at $75^{\circ} \mathrm{C}$, the $\mathrm{O}$ methylisourea 2a was formed in $60 \%$ yield, according to the ${ }^{1} \mathrm{H}$ and ${ }^{13} \mathrm{C}$ NMR spectra of the crude mixture. This result represents the first example of a metal-free catalytic synthesis of isoureas. In contrast, no conversion of the starting materials was noticed in the absence of TBD (Scheme 3). 2 a displayed no catalytic activity, showing that the process is not autocatalytic. Tertiary amines DABCO and $\mathrm{Et}_{3} \mathrm{~N}$ provided only traces of $\mathbf{2 a}$, while DMAP and DBU afforded $2 \mathrm{a}$ in low $15-24 \%$ yields. Interestingly, the $\mathrm{N}-\mathrm{H}$ functionality of TBD is crucial to maintain the catalytic activity as 
the methylated congener Me-TBD did not catalyze the formation of $2 a^{[7]}$

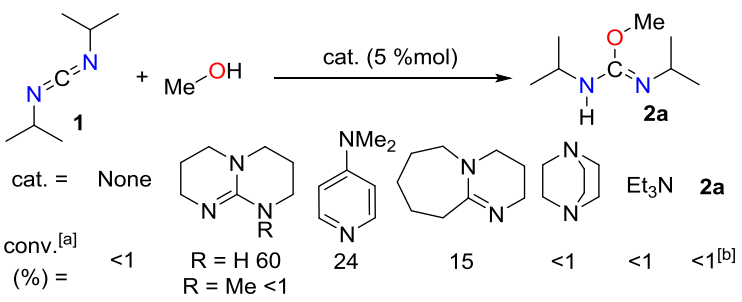

Scheme 3. Catalyst screening for the addition of methanol onto DIC. Reaction conditions: $0.5 \mathrm{mmol}$ DIC, $0.5 \mathrm{mmol} \mathrm{MeOH}, 25 \mu \mathrm{mol}$ catalyst ( $5 \% \mathrm{~mol}$ ), $600 \mu \mathrm{L}$ $\mathrm{C}_{6} \mathrm{D}_{6}, 24 \mathrm{~h}, 75^{\circ} \mathrm{C}$. [a] Determined by ${ }^{1} \mathrm{H}$ NMR of the crude reaction mixture. [b] Reaction time: 3 days.

Table 1. Catalytic reactions of DIC (1) and DTC (3) with alcohols, mediated by $\operatorname{TBD}^{[a]}$

\begin{tabular}{|c|c|c|c|c|}
\hline $\begin{array}{l}N^{\prime} \\
1 \\
\mathrm{R}\end{array}$ & $\begin{array}{l}\mathrm{R}^{\prime}=\mathrm{OH} \\
\mathrm{Pr}) \\
\text { Tolyl) }\end{array}$ & at. $=\mathrm{TBD}$ & $\begin{array}{l}\mathrm{R}^{-} \mathrm{N}^{\prime} \\
1 \\
\mathrm{H}\end{array}$ & $\begin{array}{l}\mathrm{R} \\
=i \mathrm{Pr}) \\
=p \text { Tolyl) }\end{array}$ \\
\hline Entry & $\mathrm{R}$ & $\mathrm{R}^{\prime} \mathrm{OH}$ & Time & Conv $(\%)^{[b]}$ \\
\hline 1 & \multirow{5}{*}{$\begin{array}{l}i \mathrm{Pr} \\
(\mathbf{1}, \mathrm{DIC})\end{array}$} & $\mathrm{MeOH}$ & $24 \mathrm{~h}(3 \mathrm{~d})$ & $60(90)(2 a)$ \\
\hline 2 & & $\mathrm{EtOH}$ & $24 \mathrm{~h}(3 \mathrm{~d})$ & $14(29)(\mathbf{2 b})$ \\
\hline 3 & & $\mathrm{PrOH}$ & $24 \mathrm{~h}(3 \mathrm{~d})$ & $5(9)(2 c)$ \\
\hline 4 & & $t \mathrm{BuOH}$ & $3 d$ & $<1(2 d)$ \\
\hline 5 & & $\mathrm{PhOH}^{[\mathrm{c}]}$ & $6 \mathrm{~h}$ & $50(2 e)$ \\
\hline 6 & \multirow{5}{*}{$\begin{array}{l}\text { pTolyl } \\
(3, \text { DTC })\end{array}$} & $\mathrm{MeOH}$ & $24 \mathrm{~h}(3 \mathrm{~d})$ & $73(94)(4 a)$ \\
\hline 7 & & $\mathrm{EtOH}$ & $24 \mathrm{~h}(3 \mathrm{~d})$ & $57(86)(4 b)$ \\
\hline 8 & & $\mathrm{PrOH}$ & $24 \mathrm{~h}(3 \mathrm{~d})$ & $43(68)(4 c)$ \\
\hline 9 & & $t \mathrm{BuOH}$ & $3 d$ & $<1(4 d)$ \\
\hline 10 & & $\mathrm{PhOH}$ & $6 \mathrm{~h}$ & $93(4 e)$ \\
\hline
\end{tabular}

[a] Reaction conditions: $0.25 \mathrm{mmol}$ carbodiimide, $0.25 \mathrm{mmol}$ alcohol, 13 $\mu \mathrm{mol}$ TBD $(5 \mathrm{~mol} \%), 600 \mu \mathrm{L} \mathrm{C} \mathrm{C}_{6} \mathrm{D}_{6}, 75^{\circ} \mathrm{C}$. [b] Determined by ${ }^{1} \mathrm{H}$ NMR of the crude reaction mixture. [c] $44 \%$ yield was observed without catalyst in $6 \mathrm{~h}$ and $50 \%$ maximum yield was observed at $75^{\circ} \mathrm{C}$ overnight, in agreement with the formation of the adduct $\left[\mathbf{e H}^{+}\right]\left[\mathrm{PhO}^{-}\right]$, as observed by Lloyd-Jones et al..$^{[2 c]}$

The scope of the reaction was further explored with two representative carbodiimides: diisopropylcarbodiimide (DIC) and N,N'-1,3-di-p-tolylcarbodiimide (DTC) (Table 1). The aromatic carbodiimide DTC is more reactive than DIC, due to its greater electrophilicity and, for example, isourea $\mathbf{4 a}$ was obtained in $73 \%$ yield after $24 \mathrm{~h}$ at $75{ }^{\circ} \mathrm{C}$ ( vs $60 \%$ yield for $2 \mathrm{a}$ ). The reaction is sensitive to the steric congestion on the alcohol and the yield decreased from $73 \%$ to 57 and $43 \%$ upon addition of DTC to methanol, ethanol and isopropanol, respectively. Nonetheless, increased reaction times ( 3 days) enabled the formation of $4 a-c$ in good yields (68-94\%). The isopropyl congeners 2a-c were obtained in $9-90 \%$ yield. $\mathrm{tBuOH}$ was found unreactive under the applied reaction conditions, regardless the nature of the carbodiimide (Entries 4 and 9 in Table 1). The formation of both DIC- and DTC-derived O-phenylisoureas (resp. 2e and 4e) using phenol was performed with moderate to excellent yields ( $50 \%$ and 93\%, Entries 5 and 10, Table 1).

As TBD has a $\mathrm{pK}_{\mathrm{a}}$ of 26 (in acetonitrile) somewhat lower than aliphatic alcohols, the catalytic activity of the parent alkali salts (TBDM, M $=\mathrm{Li}, \mathrm{Na}, \mathrm{K}$ ) was thus tested, reasoning that these stronger bases would facilitate the activation of the alcohol. Interestingly, while TBDM salts have been used as ligands in coordination chemistry, they have not been utilized as catalysts so far. ${ }^{[8]}$ To our delight, $\mathrm{tBuOH}$ was converted to $2 \mathrm{~d}$ in $55 \%$ yield after 3 days, when reacted with DIC, in the presence of TBDLi. The sodium and potassium salts TBDNa and TBDK exhibited an increased reactivity, enabling the formation of $\mathbf{2 d}$ in $>57 \%$ yield after only $5 \mathrm{~h}$ at $75^{\circ} \mathrm{C}$ (Entries 2 and 3 in Table 2).

Table 2. Catalytic reactions of DIC and DTC with alcohols mediated by alkali TBD salts ${ }^{[a]}$

\begin{tabular}{|c|c|c|c|c|c|}
\hline & 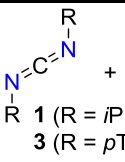 & $\begin{array}{l}\mathrm{R}^{\prime}-\mathrm{OH} \\
\text { lyl) }\end{array}$ & $=\operatorname{TBDM}(5 \mathrm{~mol} \%)$ & 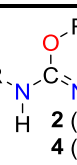 & $\begin{array}{l}\mathrm{R} \\
=i \mathrm{Pr}) \\
=p \text { Tolyl) }\end{array}$ \\
\hline Entry & $\mathrm{R}$ & R'OH & Catalyst (TBDM) & Time & Conv $(\%)^{[b]}$ \\
\hline 1 & \multirow{5}{*}{$\begin{array}{l}\operatorname{Pr} \\
(\mathbf{1}, \mathrm{DIC})\end{array}$} & \multirow{5}{*}{$t \mathrm{BuOH}$} & TBDLi & $5 \mathrm{~h}$ & $<1\left(55^{[\mathrm{d}]}\right)(2 \mathrm{~d})$ \\
\hline 2 & & & TBDNa & $5 \mathrm{~h}$ & $58(2 d)$ \\
\hline 3 & & & TBDK & $5 \mathrm{~h}$ & 57 (2d) \\
\hline 4 & & & [TBD][(18-C-6)K] & $5 \mathrm{~h}$ & $55(2 d)$ \\
\hline 5 & & & {$[\mathrm{TBD}][(2,2,2-\mathrm{B}) \mathrm{K}]$} & $5 \mathrm{~h}$ & $4(2 d)$ \\
\hline 6 & \multirow{6}{*}{$\begin{array}{l}\operatorname{Pr} \\
(\mathbf{1}, \mathrm{DIC})\end{array}$} & $\mathrm{MeOH}$ & TBDK & $1 \mathrm{~h}$ & $93(\mathbf{2 a})$ \\
\hline 7 & & \multirow{2}{*}{$\mathrm{EtOH}$} & TBDK & $1 \mathrm{~h}$ & $97(\mathbf{2 b})$ \\
\hline 8 & & & $\mathrm{TBDK}^{[\mathrm{c}]}$ & $2 \mathrm{~h}$ & $97(\mathbf{2 b})$ \\
\hline 9 & & iPrOH & TBDK & $1 \mathrm{~h}$ & 98 [82] (2c) \\
\hline 10 & & $\mathrm{PhOH}$ & TBDK & $6 \mathrm{~h}$ & $50(2 e)$ \\
\hline 11 & & $\mathrm{nC}_{12} \mathrm{H}_{25} \mathrm{OH}$ & TBDK & $1 \mathrm{~h}$ & $99(\mathbf{2 f})$ \\
\hline 12 & \multirow{5}{*}{$\begin{array}{l}p \text { Tolyl } \\
(3, \text { DTC) }\end{array}$} & $\mathrm{MeOH}$ & TBDK & $1 \mathrm{~h}$ & $92(\mathbf{4 a})$ \\
\hline 13 & & $\mathrm{EtOH}$ & TBDK & $1 \mathrm{~h}$ & $91(\mathbf{4 b})$ \\
\hline 14 & & $\mathrm{PrOH}$ & TBDK & $1 \mathrm{~h}$ & $88(4 c)$ \\
\hline 15 & & $t \mathrm{BuOH}$ & TBDK & $6 \mathrm{~h}$ & $80[76](4 d)$ \\
\hline 16 & & $\mathrm{PhOH}$ & TBDK & $1 \mathrm{~h}$ & $78(4 e)$ \\
\hline
\end{tabular}

[a] Reaction conditions: $0.25 \mathrm{mmol}$ carbodiimide, $0.25 \mathrm{mmol} \mathrm{R}^{\prime} \mathrm{OH}, 13 \mu \mathrm{mol}$ catalyst (5 mol\%), $600 \mu \mathrm{L} \mathrm{C}{ }_{6} \mathrm{D}_{6}, 75^{\circ} \mathrm{C}$. [b] Determined by ${ }^{1} \mathrm{H}$ NMR of the crude reaction mixture, isolated yield in square brackets. [c] Only $1 \mathrm{~mol} \%$ of TBDK was used. [d] Reaction time: $3 \mathrm{~d}$

Overall, TBDK exhibited an excellent catalytic activity in the conversion of the investigated alcohols, both with DIC and DTC, and isoureas $\mathbf{2 a - d , ~} \mathbf{2}$, and $\mathbf{4 a - e}$ were obtained in $>78 \%$ yield within hours at $75^{\circ} \mathrm{C}$ (Table 2). This transition metalfree catalyst hence displays a somewhat greater catalytic activity than the uranium and thorium silylamides. For instance, the O-ethylisourea $\mathbf{2 b}$ is formed in $97 \%$ yield from ethanol and DIC, in the presence of $1 \mathrm{~mol} \%$ TBDK, after $2 \mathrm{~h}$ at $75{ }^{\circ} \mathrm{C}$. Under the same conditions, a yield of $83 \%$ was measured with $\mathrm{U}\left[\mathrm{N}\left(\mathrm{SiMe}_{3}\right)_{2}\right]_{3}$ as a catalyst $(1 \mathrm{~mol} \%)$ and a reaction time of 12 h. ${ }^{[4 \mathrm{~b}]}$ The activity of TBDK prompted us to investigate the synthesis of a guanidine by addition of diethylamine onto DIC. A modest $21 \%$ yield was noted after $24 \mathrm{~h}$, which is in the same range than the yields reported by Eisen with actinide-based catalysts $(23-31 \%) .{ }^{[4 b]}$

The difference in reactivity between TBDLi and TBDK suggests that the alkali cation plays a significant role in the catalytic activity. Although alkali metal salts are rarely used as catalysts, MeONa, 
$\mathrm{MeOK}$, and $\mathrm{NaOH}$ have been reported to catalyze transamidation and transesterification reactions ${ }^{[0]}$ and the Meerwein-PonndorfVerley hydrogen transfer ${ }^{[10]}$. Yet, the catalytic role of alkali cations is generally overlooked. It is arguable that alkali cations are not simple spectator counter ions and Walsh et al. recently exploited cation- $\pi$ interactions to control the regiochemistry of crosscoupling reactions with bimetallic $\mathrm{Pd} / \mathrm{K}$ catalysts. ${ }^{[11]}$ In this context, the influence of chelating ligands, namely the 18-C-6 crown ether and the 2,2,2-B cryptand, was investigated to tune the coordination environment of potassium and modify its Lewis acidity. Both 18-C-6 and 2,2,2-B form stable complexes with $\mathrm{K}^{+}$ $\left(K>10^{6}\right) .{ }^{[12]}$ Yet, $2,2,2-B$ saturates the coordination sphere of $\mathrm{K}^{+}$ (coordination number $\mathrm{CN}=8$ ), when the $(18-\mathrm{C}-6) \mathrm{K}^{+}$complex has a CN of 6 . Interestingly, while the addition of the 18-C-6 crown did not impact the activity of TBDK, the presence of the 2,2,2-B cryptand completely cancels it out (Entry 5 in Table 2), thereby demonstrating the positive influence of the Lewis acidity of $\mathrm{K}^{+}$on the kinetics.

From a mechanistic perspective, two pathways may account for the catalytic behaviour of TBD (Scheme 4). In a first option (Route A), the nitrogen base forms an adduct with the carbodiimide prior to the addition of the alcohol. Experimentally, the formation of a stable bis-guanidine $\mathbf{5}$ has indeed been characterized recently by our group from DIC and TBD. ${ }^{[6]}$ Nonetheless, DFT calculations suggest a high energy barrier of $\Delta G^{+}=47.8 \mathrm{kcal}^{\mathrm{mol}} \mathrm{mol}^{-1}$ for this route, via $\mathbf{T S}_{1}$ (see $\mathrm{SI}$ for computation details). This activation energy is incompatible with a catalytic reaction proceeding at $75^{\circ} \mathrm{C}$ and it is higher in energy than the non-catalytic path $\left(\Delta G^{\ddagger}=\right.$ $35.8 \mathrm{kcal}^{\mathrm{mol}}{ }^{-1}$, see SI). Alternatively, a catalytic cycle based on the activation of methanol (7) and the subsequent addition to DIC (Route B) only involves an activation barrier of $\Delta G^{\ddagger}=$ $25.2 \mathrm{kcal}^{\mathrm{mol}}{ }^{-1}$. In the corresponding transition state $\left(\mathbf{T S}_{2}\right)$, the O$\mathrm{H}$ functionality is activated by the basic $\mathrm{N}$-center of guanidine while an $\mathrm{H}$-bond forms between the $\mathrm{N}-\mathrm{H}$ group of TBD and the DIC electrophile. $\mathbf{T S}_{2}$ connects to the zwitterion $\mathbf{8}$ which in turns releases the O-methylisourea $2 \mathrm{a}$ and TBD, with an overall energy balance of $-5.6 \mathrm{kcal} \mathrm{mol}^{-1} .{ }^{[13]}$ This chemical behavior explains the need for an ambiphilic catalyst, as noted from the comparison of TBD and Me-TBD (Scheme 3). This highlights again the key role of $\mathrm{H}$-bonded bifunctional adducts in the course of guanidinecatalyzed systems (Scheme 2). ${ }^{[5 c-f]}$

Replacing the $\mathrm{N}-\mathrm{H}$ group of TBD with an $\mathrm{N}-\mathrm{K}$ functionality significantly boosted the catalytic activity. Addition of TBDK to methanol was computed to form a stable adduct, $7_{\mathrm{K}}(\Delta G=-$ $6.7 \mathrm{kcal}^{\mathrm{mol}} \mathrm{m}^{-1}$ ), whereas the deprotonation of $\mathrm{MeOH}$ with TBDK is endergonic $\left(\Delta G=3.5 \mathrm{kcal} \mathrm{mol}^{-1}\right)$ (Scheme 5 and Figure S37). ${ }^{[14]}$ Reaction of $7 \mathrm{k}$ with DIC then proceeds via $\mathrm{TS}_{3}$, which lies $7.4 \mathrm{kcal}^{\mathrm{mol}} \mathrm{m}^{-1}$ above the reactants. The resulting energy span is thus low, at $14.1 \mathrm{kcal}^{\mathrm{mol}}{ }^{-1}$, i.e. $10.7 \mathrm{kcal}^{\mathrm{mol}}{ }^{-1}$ smaller than the corresponding span with TBD. Experimentally, the quantitative formation of $7 \mathrm{k}$ was observed by ${ }^{1} \mathrm{H}$ and ${ }^{13} \mathrm{C} \mathrm{NMR}$ when $\mathrm{MeOH}$ was added to a benzene- $d_{6}$ solution of TBDK. Interestingly, no reaction occurs when one equiv. of DIC was added, in line with the potential energy surface depicted in Scheme 5, which shows that $7 \mathrm{~K}$ is more stable than isourea $\mathbf{2 a}$. Catalytic conditions must thus be utilized to observe turnover and addition of a second equiv. methanol indeed resulted in the formation of $2 a$ along with $7 k$ within $1 \mathrm{~h}$ (see SI).
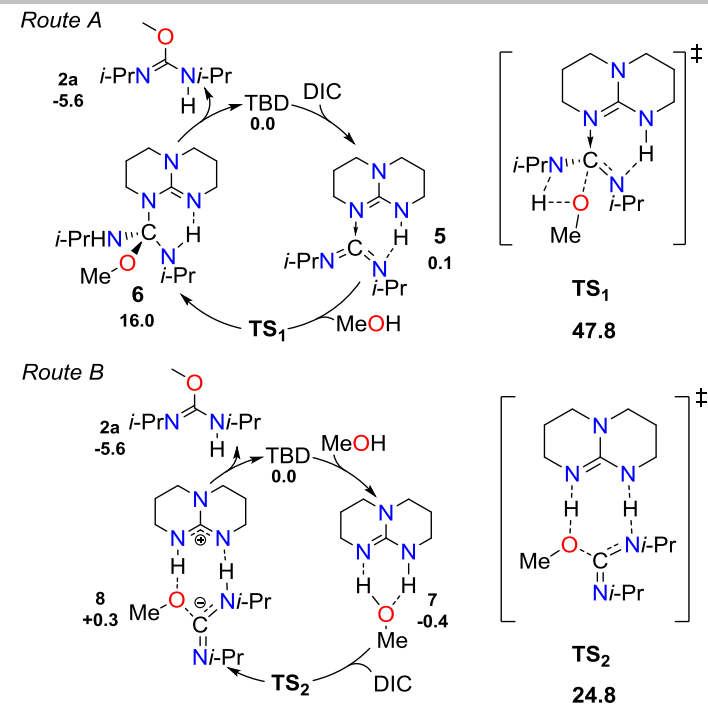

$\mathrm{TS}_{2}$

24.8

Scheme 4. Insertion of $\mathrm{MeOH}$ onto DIC catalyzed by TBD. Computed Gibbs free energies in $\mathrm{kcal}^{\mathrm{mol}}{ }^{-1}$ at the $\mathrm{M} 052 \mathrm{x} / 6-311++\mathrm{G}^{* *} / \mathrm{PCM}$ level of theory.

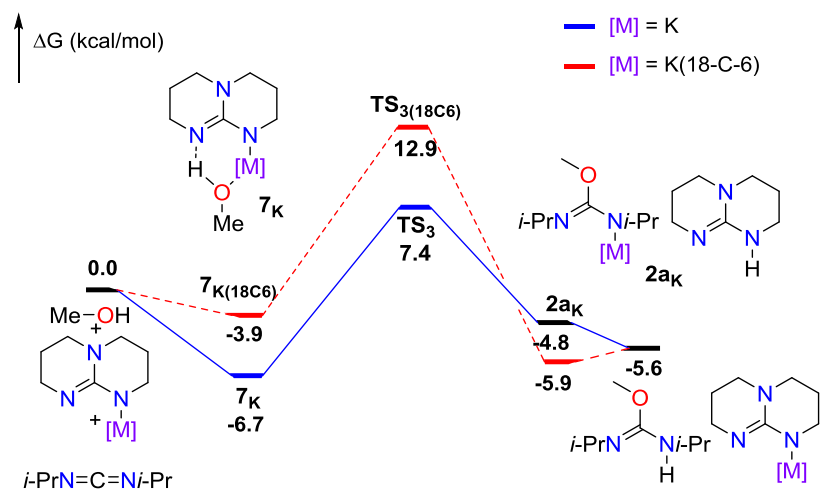

Scheme 5. Insertion of $\mathrm{MeOH}$ onto DIC catalyzed by TBDK in the presence or the absence of $18-\mathrm{C}-6$ crown ether. Computed free energies in $\mathrm{kcal}^{\mathrm{mol}}{ }^{-1}$ at the M052x/6-311++G* $(\mathrm{C}, \mathrm{H}, \mathrm{O}, \mathrm{N}) ; 6-31+\mathrm{G}^{*}(\mathrm{~K}) / \mathrm{PCM}$ level of theory.

$\mathrm{TS}_{3}$ shows that the guanidinate catalyst activates the $\mathrm{O}-\mathrm{H}$ bond of the alcohol, thereby increasing its nucleophilicity. At the same time, the potassium cation coordinates to the three main reagents, $\mathrm{TBD}^{-}, \mathrm{MeOH}$ and $\mathrm{DIC}$ and facilitates the formation of the $\mathrm{O}-\mathrm{C}$ bond. This ambiphilic behavior requires three coordination sites on the alkali metal. To determine the influence of the Lewis acidity of the alkali cation on the position of $\mathbf{T S}_{3}$, calculations were reproduced with a (18-C-6) $\mathrm{K}^{+}$environment (Scheme 5). The decreased Lewis acidity of (18-C-6) $\mathrm{K}^{+}$leads to longer O-K and $\mathrm{N}-\mathrm{K}$ bonds (Scheme 6) and results in a somewhat higher transition state at $12.9 \mathrm{kcal} \cdot \mathrm{mol}^{-1}$ but also in a destabilization of the adduct between $\operatorname{TBDK}(18-\mathrm{C}-6)$ and $\mathrm{MeOH} \quad(\Delta G=$ $\left.3.9 \mathrm{kcal} \cdot \mathrm{mol}^{-1}\right)$. In consequence, the corresponding span remains low, at $16.8 \mathrm{kcal} \cdot \mathrm{mol}^{-1}$. In contrast, when the potential energy surface is computed in the absence of $\mathrm{K}^{+}$the span increases to $37.9 \mathrm{kcal} . \mathrm{mol}^{-1}$, i.e. $2.1 \mathrm{kcal}^{\mathrm{mol}}{ }^{-1}$ higher than the non-catalytic reaction (see $\mathrm{SI}$ ). These calculations clearly explain the influence of chelating ligands on the catalytic activity of TBDK: while 18-C6 doesn't affect the efficiency of the transformation, saturation of the coordination sphere of $\mathrm{K}^{+}$with the cryptand 2,2,2-B quenches the activity of TBDK. ${ }^{[15]}$ 
In conclusion, we have described the first transition metal-free catalysts able to promote the formation of isoureas by addition of alcohols to carbodiimides. The TBD guanidine and its alkali metal salts are efficient catalysts and their ambiphilic character enables the activation of the alcohol nucleophile through $\mathrm{H}$-bonding to the basic guanidine and activation of the carbodiimide electrophile, by coordination to the alkali cation or the proton of TBD.

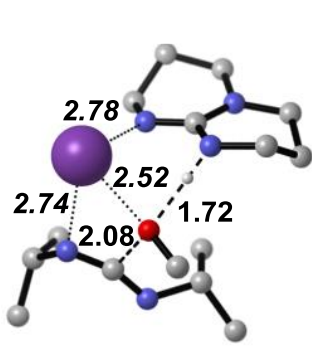

$\mathrm{TS}_{3}$

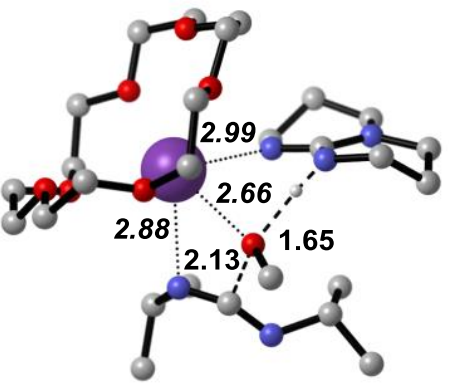

$\mathrm{TS}_{3(18 \mathrm{C} 6)}$
Scheme 6. Computed transition states with TBDK in the presence or the absence of $18-\mathrm{C}-6$ crown ether. Bond lengths in the coordination sphere of $\mathrm{K}^{+}$ are in italics. Distances in Angstrom $(\AA)$. Graphic representation by CYLview. ${ }^{[16]}$

\section{Acknowledgements}

The authors acknowledge for financial support of this work: CEA, CNRS, CINES (project sis6494), the CHARMMMAT Laboratory of Excellence, and the European Research Council (ERC Starting Grant Agreement no. 336467).

Keywords: organocatalysis - alkali metals $\cdot$ isoureas $\cdot$ density functional theory calculations $\cdot$ carbodiimides

[1] a) US Pat., 1985, 4452 627; b) M. Ogawa, T. Matsui, K. Oyamada, J. Tobitsuka, Plant Cell Physiol. 1977, 848, 841848 ; c) R. B. Barlow, Introduction to Chemical Pharmacology Moscow, 1959; d) US Pat., 1973, 3705 250; e) L. Badache, F. Boschet, Z. Lehanine, B. Boutevin, B. Ameduri, J. Fluor. Chem. 2011, 132, 382-388; f) BRD Pat., 1994, 4213 703; g) M. M. Werber, Anal. Biochem. 1976, 76, 177-183.

[2] a) Y. Inoue, M. Taguchi, H. Hashimoto, Synthesis (Stuttg). 1986, 1986, 332-334; b) A. A. Bakibaev, V. V Shtrykova Russ. Chem. Rev. 1995, 64, 929-938; c) J. A. Tate, G. Hodges, G. C. Lloyd-Jones, European J. Org. Chem. 2016, 2016, 2821-2827.

[3] a) E. Schmidt, F. Moosmüller, Justus Liebigs Ann. Chem. 1955, 597, 235-240; b) E. Schmidt, W. Carl, Justus Liebigs Ann. Chem. 1961, 639, 24-31; c) S. E. Forman, C. A. Erickson, H. Adelman, J. Org. Chem. 1963, 28, 2653-2658; d) E. Däbritz, Angew. Chemie Int. Ed. English 1966, 5, 470477; e) L. J. Mathias, Synthesis (Stuttg). 1979, 1979, 561576; f) E. Vowinkel, I. Büthe, Chem. Ber. 1974, 107, 13531359; g) A. Williams, I. T. Ibrahim, Chem. Rev. 1981, 81, 589-636.

[4] a) I. S. R. Karmel, M. Tamm, M. S. Eisen, Angew. Chemie Int. Ed. 2015, 54, 12422-12425; b) R. J. Batrice, C. E. Kefalidis, L. Maron, M. S. Eisen, J. Am. Chem. Soc. 2016, 138, 2114-2117; c) R. J. Batrice, M. S. Eisen, Chem. Sci. 2016, 7, 939-944.

[5] a) M. K. Kiesewetter, M. D. Scholten, N. Kirn, R. L. Weber, J. L. Hedrick, R. M. Waymouth, J. Org. Chem. 2009, 74, 9490-9496; b) M. Alves, R. Méreau, B. Grignard, C. Detrembleur, C. Jérôme, T. Tassaing, RSC Adv. 2017, 7, 18993-19001; c) J. Li, W.-Y. Jiang, K.-L. Han, G.-Z. He, C. Li, J. Org. Chem. 2003, 68, 8786-8789; d) Z. Jiang, Y. Pan, Y. Zhao, T. Ma, R. Lee, Y. Yang, K.-W. Huang, M. W. Wong, C.-H. Tan, Angew. Chemie - Int. Ed. 2009, 48, 3627-3631 e) B. Cho, C.-H. Tan, M. W. Wong, Org. Biomol. Chem. 2011, 9, 4550-4557; f) for a review on the mechanistic aspects of guanidine-catalyzed reactions, see X. Fu, C.-H. Tan, Chem. Commun. 2011, 47, 8210-8222.

[6] a) C. Das Neves Gomes, O. Jacquet, C. Villiers, P. Thuéry, M. Ephritikhine, T. Cantat, Angew. Chemie - Int. Ed. 2012 51, 187-190; b) N. von Wolff, C. Villiers, P. Thuéry, G Lefèvre, M. Ephritikhine, T. Cantat, Eur. J. Org. Chem. 2017, 2017, 676-686.

[7] Note that the basicity of TBD and Me-TBD are similar as the protonation of the nitrogen atom is characterized by $\mathrm{pK}_{\mathrm{a}} \mathrm{S}$ of 26 and 25.4 in acetonitrile, respectively. See M. Aresta, A. Dibenedetto, E. Fracchiolla, P. Giannoccaro, C. Pastore, I. Pápai, G. Schubert, J. Org. Chem. 2005, 70, 6177-6186.

[8] a) A. A. Mohamed, A. P. Mayer, H. E. Abdou, M. D. Irwin, L. M. Pérez, J. P. Fackler, Inorg. Chem. 2007, 46, 1116511172 ; b) C. Neuhäuser, M. Reinmuth, E. Kaifer, H.-J. Himmel, Eur. J. Inorg. Chem. 2012, 2012, 1250-1260.

[9] a) T. Ohshima, Y. Hayashi, K. Agura, Y. Fujii, A. Yoshiyama, K. Mashima, Chem. Commun. 2012, 48, 5434; b) A. Ramirez, B. Mudryk, L. Rossano, S. Tummala, J. Org. Chem. 2012, 77, 775-779. c) K. Agura, T. Ohshima, Y. Hayashi, K. Mashima, Org. Synth. 2014, 91, 201-210; d) S. Ma, C. Liu, R. J. Sablong, B. A. J. Noordover, E. J. M. Hensen, R. A. T. M. van Benthem, C. E. Koning, ACS Catal. 2016, 6, 6883 6891; e) B. Testud, D. Pintori, E. Grau, D. Taton, H. Cramail, Green Chem. 2017, 19, 259-269.

[10] a) A. Ouali, J. P. Majoral, A. M. Caminade, M. Taillefer, ChemCatChem 2009, 1, 504-509; b) V. Polshettiwar, R. S. Varma, Green Chem. 2009, 11, 1313-1316.

[11] a) J. Zhang, A. Bellomo, N. Trongsiriwat, T. Jia, P. J. Carroll, S. D. Dreher, M. T. Tudge, H. Yin, J. R. Robinson, E. J. Schelter, P. J. Walsh, J. Am. Chem. Soc. 2014, 136, 62766287; b) J. Zhang, S.-C. Sha, A. Bellomo, N. Trongsiriwat, F. Gao, N. C. Tomson, P. J. Walsh, J. Am. Chem. Soc. 2016, 138, 4260-4266.

[12] a) J. M. Lehn, J. P. Sauvage, J. Am. Chem. Soc. 1975, 97, 6700-6707; b) M. Hiraoka, in Stud. Org. Chem., Elsevier Scientific, Tokyo, 1982, p. 12.

[13] The hypothesis of an auto-catalytic reaction implying an isourea as a proton shuttle was also ruled out due to a high barrier $\left(\Delta G^{\ddagger}=30.6 \mathrm{kcal} \cdot \mathrm{mol}^{-1}\right.$, see SI), in line with the experimental results (Scheme 3 ).

[14] Kinetic studies monitored by ${ }^{1} \mathrm{H}$ NMR spectroscopy revealed that the rate-determining step of the overall process follows a first-order behavior in catalyst (see $\mathrm{SI}$ ), which led us to consider one active TBDK in the DFT computational analysis. [15] In order to take into account a possible role of benzene coordination on the $\mathrm{K}^{+}$cation in the TBDK-catalyzed pathways, the corresponding surfaces involving the solvated $\left(\eta^{6}-\mathrm{C}_{6} \mathrm{H}_{6}\right) \mathrm{K}^{+}$cation have been computed (see $\left.\mathrm{SI}\right)$. Benzene coordination only led to a negligible increase of the energy span by $0.8 \mathrm{kcal}^{\mathrm{mol}}{ }^{-1}$.

[16] C. Y. Legault, CYLview, 1.0b, Université de Sherbrooke, 2009, http://www.cylview.org. 